\title{
Seasonal variations of organic carbon in the sediments of Imphal River, Manipur
}

\author{
Khuraijam Usha $^{1}$, K. Khelchandra Singh ${ }^{2}$ \\ ${ }^{1}$ Department of Environmental Science, D.M. College of Science, Imphal 795001, Manipur, India \\ ${ }^{2}$ Department of Environmental Science, Pachhunga University College, Aizawl 796001, Mizoram, India \\ Corresponding author: khuraijamusha36@gmail.com
}

\begin{abstract}
The Imphal River is major river in Manipur, India, that connects Manipur River and Bay of Bengal. The seasonal variations of organic carbon in surface sediments and the major sources along the course of the river were studied. Sediment samples were collected from five sampling sites, namely Lamlong Thong (Site 1), Minuthong (Site 2), Sanjenthong (Site 3), Bamon leikai (Site 4) and Singjamei Leishangthem leikai (Site 5). Organic carbon contents were determined using the Walkley-Black rapid back titration method. It varied considerably in different seasons as well as between different sampling sites. Highest organic carbon was at Site $3(2.76 \%)$ in the winter season, whereas lowest was at Site $4(1.29 \%)$ in the monsoon season. The highest organic carbon at Site 3 may be attributed to large amount of organic matter released from the Sanjenthong residential area and the cumulative effect of organic matter from municipal deposition in the upstream area. There is no proper mechanism of waste disposal, as inhabitants dumped waste directly into the river. The seasonal variation is also partly due to sedimentation of the dissolved and suspended particles found in the river. Site 1 and Site 4 are kept comparatively cleaner. People cultivate crops and they do not dump wastes into river as traditional dumping sites are properly maintained especially at site 1 and 4 . Incidentally, lower organic carbon values were recorded from these sites.
\end{abstract}

Keywords: Organic carbon, variation, sediment, Imphal River, Manipur.

\section{INTRODUCTION}

In aquatic environment, organic matter plays a pivotal role as it affects the biogeochemical and nutrient cycling, biological availability, chemical transport and other interactions (Niemirycz, 2006). Wetland acts as an important carbon pool in terrestrial ecosystem (Cao et al., 2017). The amount of organic carbon content in the river sediment is not only due to natural sources but also disposal of organic waste and various human induced polluting activities. Such targeted actions altered the organic carbon content in the rivers of the world. Globally, the total organic carbon transported by rivers is only about $1-2 \%$ of the net primary productivity of any environment (Meybeck, 1982).

The amount of carbon content in the soil differs according to the places where the river flow, river course, season of sample collection, pollution entering rivers. If the pollution load contains high amount of organic matter, then it will lead to elevated levels of organic carbon in the sediment. The concentration of organic carbon in surface sediment is dependent on a number of factors like sedimentary features, microbial decomposition rates, productivity in water bodies and terrestrial based input (Burone et al., 2003).

Variation of organic carbon in river sediment has been studied by various workers such as Bin et al. (2011), Gao et al. (2012), Paropkari (1979) in North Western Continental shelf, India, Dinakaran and Krishnayya (2011) in Mahi river, India, Bouillon et al. (2003) in Gautami Godavari Estuary, India, Cao et al. (2015) in Northern Chinese rivers, Li et al. (2017) in Yangtze river and Yellow river, China, Burone et al. (2003) in Ubatuba Bay, Brazil. Study of the seasonal variation of organic carbon in the surface sediments of rivers is of prime importance to 
know the environmental condition. The main aim of this study is to determine the organic carbon content in the sediment of the Imphal River and to identify the major sources of organic carbon inputs along the course of Imphal River.

\section{MATERIALS AND METHODS}

The present study was carried out on Imphal River, Manipur. The study site map is presented in Figure 1. Sediments samples were collected from five different sampling sites namely; Site 1 - Lamlong Thong, Site 2 Minuthong, Site 3 - Sanjenthong, Site 4 - Bamon Leikai, Site 5 - Singjamei Leisangthem Leikai. Collections of the sediment sample were done from the five sampling sites during the study period 2016 and 2017. The concentration of organic carbon is estimated using the method describe by Walkley and Black (1934). Collected samples are brought to the laboratory and kept in oven for drying. Organic carbon content in the sediments is dissolved by using an active oxidising agent The reaction is assisted by the heat generated when two volumes of sulphuric acid are mixed with one volume of the potassium dichromate. The remaining dichromate is titrated with ferrous ammonium sulphate using diphenylamine Indicator.

\section{RESULTS}

The variation of the organic carbon in sediments of Imphal River are presented in Table 1. In Site 1 (Lamlong Thong) the organic carbon content ranges from $1.65 \%$ (monsoon) to $1.95 \%$ (winter), while during summer season it is $1.71 \%$. In Site 2 (Minuthong), the organic carbon varied from $1.80 \%$ (monsoon) to $2.28 \%$ (winter) and $2.10 \%$ during summer; whereas in Site 3 (Sanjenthong) the organic carbon varied between $2.04 \%$ (monsoon) to $2.76 \%$ (winter) and $2.67 \%$ during summer season. Ranges of organic carbon content in Site 4 (Bamon Leikai) exhibit lowest value of $1.29 \%$ during monsoon followed by $1.53 \%$ (summer) and highest value of $1.56 \%$ during winter season. Similarly, in Site 5 (Singjamei Leisangthem Leikai) highest organic carbon value of $2.22 \%$ was recorded in sample collected during winter season and lowest values of $1.95 \%$ (monsoon) followed successively by summer $(2.13 \%)$. It can be clearly seen from Figure 2 that the organic carbon concentration of Imphal River varied seasonally in different study site. The overall estimated value of organic carbon is found highest in samples collected from Site $3(2.76 \%)$ during winter season. However, the lowest organic carbon content during the entire study period is reported from Site 4 (1.29\%) during monsoon season.

\section{DISCUSSION}

The higher organic carbon content during the winter season recorded in the present investigation may be attributed to various factors. During winter season, there is lesser rainfall and the depth of river decreases drastically. The flow of the river becomes steadier and gentle. The garbage, domestic sewage and other solid wastes thrown into the river cannot be carried further downstream due to slow flow rate of the river water. The dead and decayed organic matter gets deposited in the river sediment brought down from various places. This leads to further accumulation of waste in a localised area. Decomposition of organic matter in sediment is an important factor for higher organic carbon content (Rajasegar et al., 2002). The rate of decomposition is higher during the summer and winter season compare to monsoon. It is evident from the findings that lower concentrations of organic carbon were reported during the monsoon season as compared to winter and summer seasons. In a study in some rivers of Manipur, higher organic carbon in sediments during summer is reported by Singh and Gupta (2015). During the monsoon season, due to surge in rainfall there is increase in depth of the river. Moreover, increase volume of river water leads to rise in the flow and volume of river water. All the waste from various sources also flows into the river. Floods also occur very frequently during the monsoon season. The deposits in the river beds also run off along with the increased velocity of water flow of the river. Additionally, lower decomposition rate coupled with dilution due to increase volume of river water may have led to lowest organic carbon content during monsoon season.

The highest concentration of organic carbon reported at Site 3 compared to other study sites may be attributed to large amount of waste released from the Sanjenthong residential area and also the growing effect of organic matter from municipal deposition in the upstream area. Lack of adequate mechanism for the disposal of waste and dumping of generated waste directly into the river by inhabitants of the area may have contributed to more organic matter in the river. Moreover, the density of population affects the organic carbon content. This is evident in the Site 3, where the highest organic carbon content is recorded from the densely populated area. It is found that at Site 1 and Site 4 area, river basins are kept comparatively cleaner. People living in the vicinity of this two study sites cultivate crops on the floodplains and they do not dump wastes directly into the river. They also have properly maintained traditional dumping sites. These may have led to lower organic carbon contents reported from the above two sites.

\section{CONCLUSION}

Organic carbon concentration in the sediment of Imphal River varies considerably in the different seasons of the study period. Highest organic carbon content is recorded from Site 3 during the winter season whereas the lowest value is found in Site 4 in the monsoon season. 


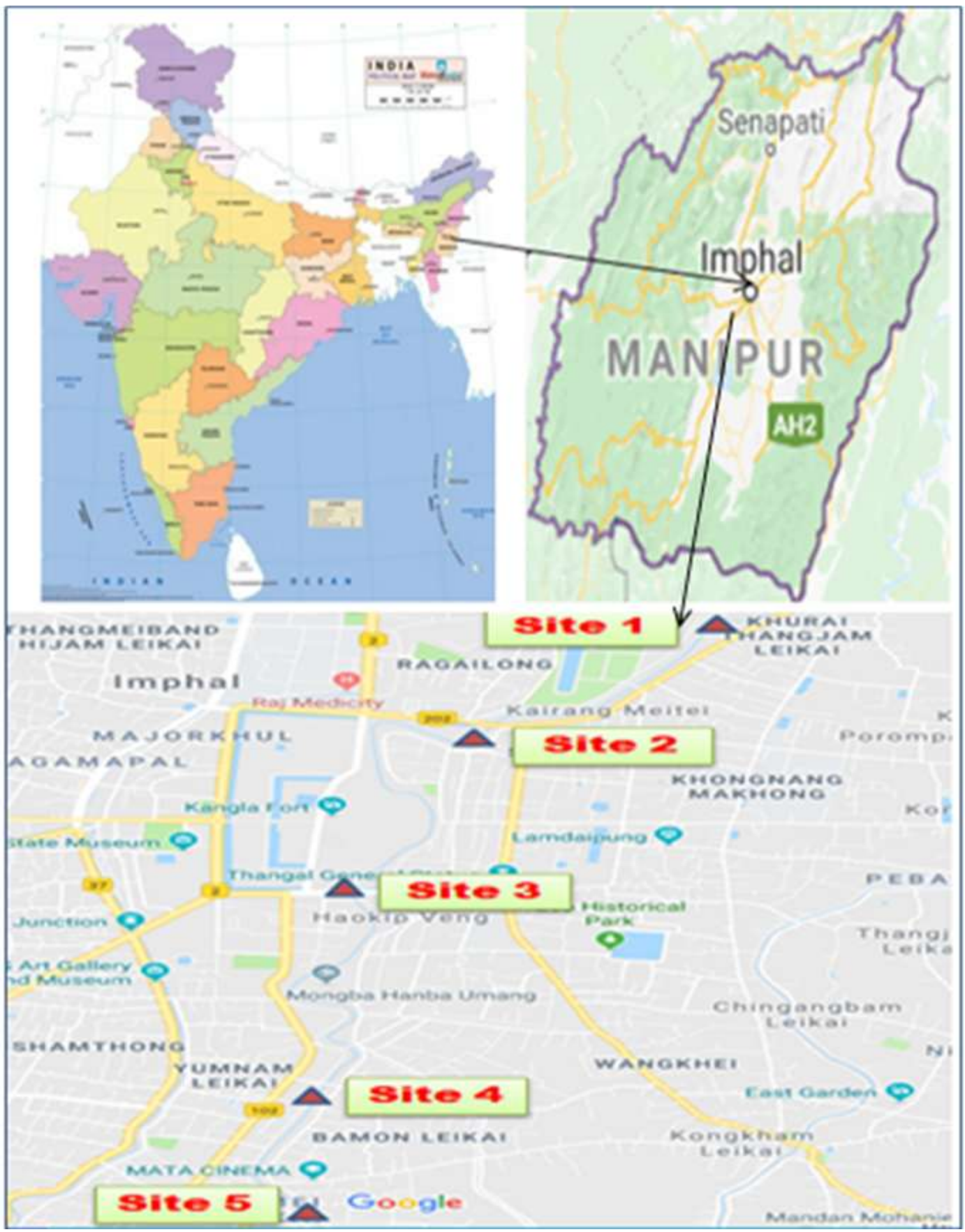

Figure 1: Study site - map showing Imphal River, Manipur.

Table 1: Variation of organic carbon in Imphal River, Manipur.

\begin{tabular}{|c|l|c|c|c|}
\hline \multirow{2}{*}{ Site } & \multicolumn{1}{|c|}{ Name of the Site } & \multicolumn{3}{|c|}{ Organic carbon content (\%) } \\
\cline { 3 - 5 } & & Summer & Winter & Monsoon \\
\hline Site 1 & Lamlong Thong & 1.71 & 1.95 & 1.65 \\
\hline Site 2 & Minuthong & 2.1 & 2.28 & 1.8 \\
\hline Site 3 & Sanjenthong & 2.67 & 2.76 & 2.04 \\
\hline Site 4 & Bamon Leikai & 1.53 & 1.56 & 1.29 \\
\hline Site 5 & Singjamiei Leisangthem Leikai & 2.13 & 2.22 & 1.95 \\
\hline
\end{tabular}




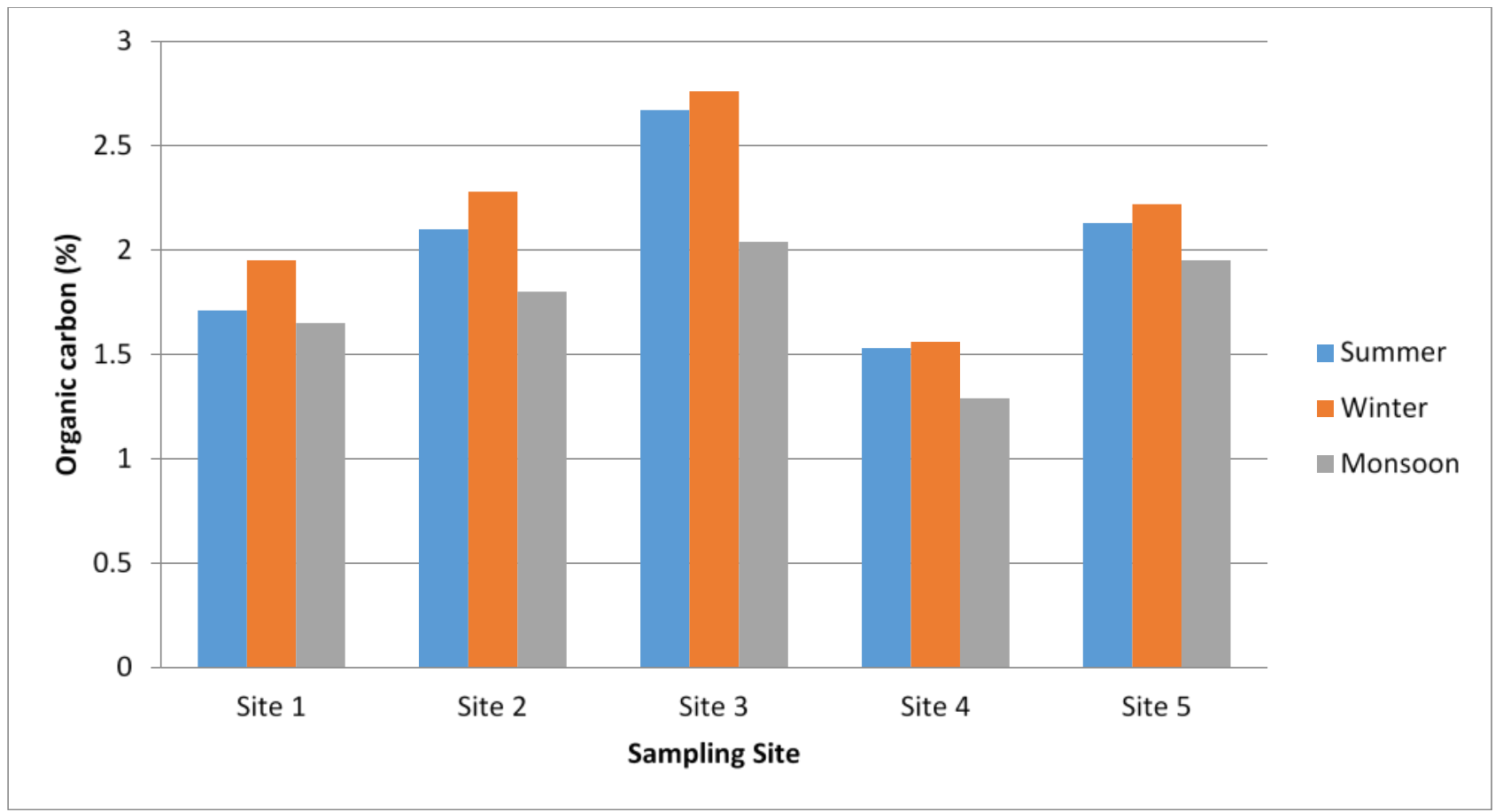

Figure 2: Seasonal variation of organic carbon in Imphal River, Manipur.

The seasonal variation of organic carbon may be partly due to sedimentation of the dissolved and suspended particles found in the river. Velocity of the flow of river is also another factor that contributes to the variation of the organic carbon seasonally. It can be seen that higher velocity of river flow corresponds to lower organic carbon content of the river. It is evident from the result that systematically maintained dumping sites along the river reported reasonably lower organic carbon content as compared to other sites.

\section{ACKNOWLEDGEMENT}

The authors are thankful to the Head, Department of Environmental Science, D.M. College of Science, Imphal, Manipur, for providing various facilities to undertake the research work. The authors would also like to sincerely thank the VI semester Environmental Science students of 2017 batch, D.M. College of Science, for helping with the project work.

\section{REFERENCES}

Bin, L., Xiuling, M., Yan, W. (2012). Spatial distribution characteristics of soil organic carbon and nitrogen in Main Wetlands in Daxing'anling. J. Northeast Forestry Univ. 3, 027.

Burone, L., Muniz, Pablo., Pires-Vanin, A.N.S., Rodriques, M. (2003). Spatial distribution of organic matter in the surface sediments of Ubatuba Bay (SoutheasternBrazil). Annals of the Brazilian Academy of Sciences,
75(1), 77-90.

Bouillon, S., Frankignoulle, M., Dehairs, F, Velimirove, B., Eiler, A., Abril, G, Etcheber, H., Borges, A.B. (2003). Inorganic and organic carbon biogeochemistry in the Gautami Gidavari Estuary (Andhra Pradesh, India) during pre-monsoon: The local impact of extensive mangrove forests. Global Biogeochemical Cycles, 17 (4), 1114.

Cao, Q. Q., Wang, R. Q., Liu, J. (2015). Composition and distribution of organic carbon in river sediments: a case study of two northern Chinese rivers. Pol. J. Environ. Stud. 24, 969.

Cao,Q,Q., Wang, H., Zhang, Y., Lal, R., Wang, R., Ge, X., Liu, J. (2017). Factors affecting distribution pattern of organic carbon in the sediments at regional and national scales in China. Scientific Reports, 7, 5497.

Dinakaran, J., Krishnayya, N.S.R. (2011). Variation in total organic carbon and grain size distribution in ephemeral river sediments in western India. International Journal of Sediment Research, 26(2), 239-246.

Gao, X., Yang, Y., Wang, C. (2012). Geochemistry of organic carbon and nitrogen in surface sediments of coastal Bohai Bay inferred from their ratios and stable isotopic signatures. M ar. Pollut. Bull. 64, 1148-1155.

Li, X., Ding, Y., Han, T. et al., (2017). Seasonal variation of total organic carbon and nitrogen in the upper basin of Yangtze river and Yellow river. Journal of Mountain Science, 14:1577.

Meybeck, M. (1982). Carbon, nitrogen and phosphorus transport by rivers. American J. Sci., 2824011450.

Niemirycz, E., Gozdek, J., Koszka-Maron, D. (2006). Variability of organic carbon in water and sediments of 
Odra River and its tributaries. Polish J. Environ. Stud, 15(4), 557-563.

Paropkari, A.L. (1979). Distribution of organic carbon in sediments of the north western continental shelf of India. Indian J. of Marine Sci, 103(3), 213-220.

Rajasegar, M., Srinivasan, M., Ajmal, K.S. (2002). Distribution of sediment nutrient of Vellar Estuary in relation to shrimp farming. Indian J. M arine Sci, 31, 153-156.
Singh, M., Gupta, A. (2015). Spatio-temporal variation in Physico-chemical properties of sediments from the Rivers of Manipur, North-east India. Pollution Research, 34(2), 401-408.

Walkley, A., Black, I. A. (1934), An examination of the Degtareff method for determining soil organic matter and proposed modification of the chromic acid titration method. Soil Science. 37, 29-38. 